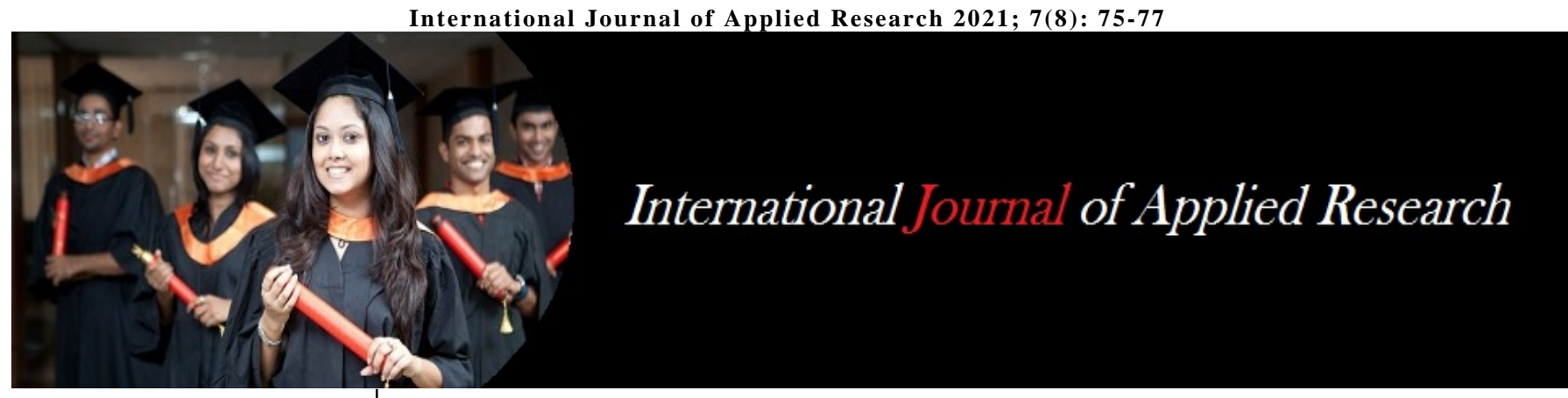

ISSN Print: $2394-7500$

ISSN Online: 2394-5869

Impact Factor: 8.4

IJAR 2021; 7(8): 75-77

www.allresearchjournal.com

Received: 04-06-2021

Accepted: 06-07-2021

Luke Ramirez-Bryan

Department of Nutrition,

West Chester University of

Pennsylvania, United States of

America

Amir Golmohamadi

Department of Nutrition,

West Chester University of

Pennsylvania, United States of

America

Hossein Vojoudi

College of Science, University

of Tehran, Tehran, Iran

\section{Declining knowledge on proper food storage and preparation causes an increase in household food waste}

\section{Luke Ramirez-Bryan, Amir Golmohamadi and Hossein Vojoudi}

DOI: https://doi.org/10.22271/allresearch.2021.v7.i8b.8824

\begin{abstract}
In 2020 in the U.S alone over 40 million tons of food were wasted. Part of this waste is attributed to discarded fruits and vegetables and equals $7 \%$ of croplands' yearly production. Reducing food waste can be an important factor in improving environmental and social sustainability. Lack or inadequate, knowledge of food preparation, storage, and cooking has contributed to this loss.

One method of reducing food wastes is decreasing the amount of waste in households by using nutrition education intervention interventions such as training local communities to improve their cooking skills and general food storage and preparation knowledge. Consumers will also be more environmentally and economically sustainable, with less food waste in each household.

The objective of this study is to prepare a report that can be used for developing nutrition education guidelines for nutrition educators, with the ultimate goal being to increase the knowledge of local residents to create a more sustainable community. This report will also partially meet the requirements of the Department of Nutrition's capstone course (NTD 450) for the Sustainable Food Systems Management concentration. This report will list and discuss the practical strategies that increase the awareness of consumers by starting a multi-platform social media campaign that posts daily tips and offers free educational classes on sustainable shopping practices, cooking lessons, and proper storage and food disposal. The ultimate goal of this project is to contribute to the sustainable development goals of the United Nations.
\end{abstract}

Keywords: food waste, sustainability, food storage

\section{Introduction}

With America being the leader in the world for food waste, wasting around 40 million pounds of food every year, there has been a need for an increase in awareness and reduction methods for food waste. The "western diet", which is a diet high in refined carbohydrates, added sugars, sodium, and animal products, and low intake of fruits, vegetables, and whole grains, has been a common dietary pattern for many individuals, and has a high environmental impact through greenhouse emissions, and land use ${ }^{[1]}$. Higher quality diets, high in fruits and vegetables, have been associated with lower greenhouse gas emissions, land and water usage. Some countries have moved to include sustainable indicators within their dietary guidelines, in hopes of reducing environmental impacts of dietary needs ${ }^{[1]}$. By optimizing diets and minimizing food waste at a household level will reduce the environmental footprint of the food chain. Individual waste accounts for about $30-40 \%$ of all food waste, and this is due to poor dietary choices, meal planning, and proper preparation, and storage of these food items. Food waste is an important indicator of sustainability, due to it being the total number of wasted resources that were used to produce this uneaten food, which ranges from water used for irrigation, to harmful pesticides that are used to treat our crops. A recent study from the U.K found that the theory of planned behavior fits well into the model of reducing individual household waste if they felt others approved of their actions, and confident in their abilities. In the U.S alone $20 \%$ of food is either lost or wasted at a consumer level., and that accounts for about 290 pounds of food waste per individual each year ${ }^{[1]}$.
Corresponding Author: Amir Golmohamadi Department of Nutrition, West Chester University of Pennsylvania, United States of America 


\section{Dietary Behavior}

At a household level, resources used for home cooking, such as a mixture of food waste, water, and disposable wet wipes, papers, and such disposed in sinks, have been found to clog sewer ways and cause water system related issues in the U.K ${ }^{[2]}$. FOGs, which stands for fat, oil, and grease, has been in the limelight of sustainability issues for some time now and improper disposal, whether the grease is disposed in the sink or other drainage point can lead to sewer blockages that can cause, flooding, property damage, and pollution via CO2 emissions. From 2011-2013 in the U.K, there has been an estimated $£ 88$ million worth of sewer blockage repairs in which $80 \%$ of that was due to FOGs and other items flushed inappropriately through home drains. The preferred prevention or intervention method of companies that are working to decrease this FOGs contamination is at the individual level. These companies have been educating individuals on the proper disposal of these FOGs, and other items used in the kitchen, by delivering letters or leaflets to all homes. Some initiatives put into place such as the "Keep it clear campaign" in the U.K, which target household FOG's waste into sewer systems, has seen a $52 \%$ decrease in blockages in sewer networks ${ }^{[2]}$. Proper disposal of FOGs includes draining them into jars or cans after cooking rather than into sinks or drains. Another study has found that an increase in the amount of food planning in a household has led to a decrease in over- purchasing food in turn reducing food wasted week to week. This same study has also suggested for lower-income households a substitute for fresh vegetables and fruits is to purchase canned goods, and when fresh produce is purchased it can be preserved by being frozen as well ${ }^{[1]}$.

Planning your trip to the grocery store and what you actually buy are intertwined with how the foods are prepared, managed, and stored, so planning ahead of time gives a higher chance of reducing household food waste as it gives ample time to prepare and store the foods. One crucial part of the food preparation process is to realize food waste can be produced indirectly and to ensure the most sustainable practice to properly dispose of said waste whether it is direct or indirect. By planning weekly grocery hauls households can make sustainable choices regarding what foods release FOGs, and other harmful indirect wastes, and when FOGs are produced, they are disposed of properly, whether it is disposed in a mason jar for later reuse or for proper disposal [2].

\section{Environmental Resources}

Food wasted in the food chain accounts for almost 30 million acres of land use to produce these foods. Along with this, almost 4.2 trillion gallons of water were used to irrigate the land of these wasted food resources, which is crucial will our declining levels of fresh drinking water. By reducing total food waste at a household level will dramatically reduce billions of tons worth of natural and chemical resources used in the production of foods that may not even be consumed.

The interconnectivity of the food chain and environmental impacts is important especially with pesticide, and fertilizer runoff from rain into local freshwater sources, and soil.

\section{Nutrition Education}

Recent studies have suggested that proper knowledge and skill development of nutrition training has been needed for the food system setting. This means that there needs to be a holistic and sustainable framework for viewing and eating foods in order to reduce food waste and increase individual sustainability [3]. Enhancing education not only at a community level, but for incoming dietetic students will help develop an adequate response to this complex issue of food system sustainability. Purchasing and planning food was a key indicator in the study of nutrition undergraduate students and their engagement with new education tactics. Through this study students reflected and journaled their results from week to week, and eventually became a learned way of being and become more effective at reflecting on their dietary changes by becoming more sustainable. They also found through this study by educating the students and having them fulfill their journaling and reflection requirements, the students developed skills in this particular complex issue of sustainability. In this study, the method of education and implementation was to introduce concepts of sustainability and educate on the various aspects of it and then have the students direct their own learning in their particular area of interest. This education method follows concepts of the theory of adult learning, andragogy, and is an effective method for teaching sustainable practices ${ }^{[4]}$.

\section{Connectivity}

Policymakers for local and governments as well as those interested in improving personal sustainability can use this information and research provided to increase education and awareness. The issue within the system itself is the lack of knowledge among the common population that sustainability can be alleviated through individual acts and conscious action.

Holding local community workshops that educate those of a certain community can raise awareness while educating those on how they can personally improve household sustainability through reducing food waste. Although having educational seminars and workshops is crucial for improving sustainability on a community level, emphasis on continual education after it ends is also necessary. Another key part of making this implementation success is to keep information in lay man's terms for all educational levels and people to comprehend and follow guidelines given to them. While this paper emphasizes on the education of the general population, education for scholarly individuals and those enrolled in collegiate studies is highly encouraged as well. Another potential implementation would be for the department of education to include sustainability education in the core curriculum. Education of personal sustainability and proper food waste disposal starting at the elementary level could be beneficial as new research can be implemented as it is released year to year. Individuals can use this literature review to learn and implement new practices into their life such as proper FOG disposal.

\section{Conclusions}

In conclusion, research has pointed that education on how to prepare and store your food has led to a decrease in household sustainability. By planning trips to the store and what to be purchased for groceries households are less likely to waste food. Along with this proper knowledge on how to dispose or FOGs and other byproducts of the cooking process is crucial for reducing sewage and water line issues. Future researchers can use this literature review to further research on prevention and reduction methods of individual 
and household food waste by researching other methods of intervention such as composting food scraps. While food waste will never be completely eliminated bringing awareness and education to this issue will help reduce this issue to a point where it hopefully has the least amount of environmental, social, and economic impact possible.

\section{Acknowledgements}

The authors wish to thank West Chester University of Pennsylvania's Office of Research and Sponsored Program.

\section{References}

1. Conrad Z, Niles MT, Neher DA, Roy ED, Tichenor NE, Jahns L. Relationship between food waste, diet quality, and environmental sustainability, PLoS One 2018;13:e0195405.

2. Foden M, Browne AL, Evans DM, Sharp L, Watson M. The water-energy-food nexus at home: New opportunities for policy interventions in household sustainability, Geogr. J. 2019;185:406-418.

3. Wilkins JL, Lapp J, Tagtow A, Roberts S. Beyond eating right: the emergence of civic dietetics to foster health and sustainability through food system change, J Hunger Environ. Nutr 2010;5:2-12.

4. Maher J, Burkhart S. Experiential learning for engaging nutrition undergraduates with sustainability, Int. J Sustain. High. Educ 2017. 